\title{
Modelling of Biphasic Biogas Production Process from Mixtures of Livestock Manure Using Bi-logistic Function and Modified Gompertz Equation
}

\author{
Christian C. Opurum $^{1^{*}}$, Christian O. Nweke ${ }^{1}$, Christopher E. Nwanyanwu ${ }^{1}$ \\ and Nkemakolam A. Nwogu ${ }^{1}$ \\ ${ }^{1}$ Department of Microbiology, Federal University of Technology, P.M.B. 1526, Owerri, Imo State, \\ Nigeria. \\ Authors' contributions \\ This work was carried out in collaboration among all authors. Author CCO designed the study, \\ performed the statistical analysis, wrote the protocol and wrote the first draft of the manuscript. \\ Authors CON and CEN managed the analyses of the study. Authors CCO and NAN managed the \\ literature searches. All authors read and approved the final manuscript.
}

Article Information

DOI: $10.9734 / A R R B / 2021 / v 36 i 330358$

Editor(s):

(1) Prof. Tunira Bhadauria, Kanpur University, India.

Reviewers:

(1) Patrick Mukumba, University of Fort Hare, South Africa.

(2) Mike U. Ajieh, Delta State University, Nigeria. Complete Peer review History: http://www.sdiarticle4.com/review-history/66379

Original Research Article

Received 07 February 2021

Accepted 15 March 2021

Published 22 April 2021

\begin{abstract}
In this study, anaerobic digestion (AD) of three livestock manure: (poultry manure (PM), pig dung (PD), and cow dung (CD) was conducted at different mixed ratios under mesophilic $\left(25-35^{\circ} \mathrm{C}\right)$ conditions. Two kinetic models, the modified Gompertz and bi-logistic function model were used to simulate the cumulative biogas yield from the experiments, and model parameters simultaneously obtained. The biogas production profile appeared diauxic-like or biphasic with multiple peaks, revealing the complexity and multi-component nature of the substrates. There was an increase in biogas yield from the treatments, PD/CD $1: 1 ; 37.25 \mathrm{dm}^{3}(3.47 \%)$, PD/CD $3: 1 ; 38.41 \mathrm{dm}^{3}(6.96 \%)$, CD/PM 1:1; $26.76 \mathrm{dm}^{3}(16.80 \%)$ and CD/PM 3:1 24.31 $\mathrm{dm}^{3}(6.11 \%)$, whereas PD/CD 2:1 (15.41 $\mathrm{dm}^{3}$ ) and CD/PM 2:1 (22.57 $\left.\mathrm{dm}^{3}\right)$ exhibited inhibitory effect. However, statistical analysis (ANOVA) indicated a significant difference in biogas yield from PD alone $\left(36 \mathrm{dm}^{3}\right)$ compared to CD alone $\left(22.91 \mathrm{dm}^{3}\right)$. The two models showed good performance in the simulation of the AD process, with high correlation coefficients, an indication of a very strong relationship between experimental data and model parameters. However, the bi-logistic function model showed a better fit in the simulation of the experimental values, as it was able to capture the curves in the plots, with a higher
\end{abstract}

*Corresponding author: E-mail: christian.opurum@futo.edu.ng, chrisopurum@gmail.com; 
correlation coefficient $R^{2}(0.9920-0.9985)$ than the modified Gompertz model $(0.9797-0.9968)$. This work has shown that the phenomenon of diauxic growth in the anaerobic digestion of complex organic substrates could be captured quantitatively in the kinetic model using bi-logistic function model.

Keywords: Anaerobic co-digestion; biogas yield; diauxic growth; kinetic model; livestock manure.

\section{INTRODUCTION}

Given the intensified agricultural activities to address global food crises and ensure food security, there has been an increased waste generation. Production of "green energy" from agro-wastes is a panacea for the challenges (energy depletion and waste management) confronting humanity as a result of climate change and natural resource vulnerabilities. Animal husbandry produces an enormous quantity of manure that poses a serious problem for the environment. Chicken droppings are mainly made up of nitrates. Nitrate pollution is noxious because of its potential role in eutrophication, methemoglobinemia, and nitrosamines formation [1] and effective treatment methods are therefore very necessary. Anaerobic digestion (AD) has proven to be an attractive and efficient pathway to this, offering multiple advantages, such as reduced pollution and emission of greenhouse gases, eliminate pathogens, biomass reduction, stabilization of wastes, and production of biogas), which is considered a competitive renewable energy source.

The application of untreated manures has been a common practice in feeding fish in the Far East for many years [2]. The growth of planktons in fish ponds has been boosted by the introduction of poultry and other livestock manures directly into the pond, but the repulsive odour tends to have an adverse effect on the palatability of the fish. The use of commercially prepared feed in fish farming is capital intensive and it is not suitable and viable in many countries. Recycling organic wastes in fish production after compositing or by fermenting the wastes in bioreactors have been an alternative method [2].

Animal manure is majorly composed of lignocellulosic fibers that were not completely digested by the animals [3]. Livestock manures are nutrient-rich soil conditioner and also a promising resource for "green energy" production by anaerobic digestion, which significantly reduces the volume and stabilizes the manure. One of the primary advantages of utilizing manures as a source of biogas production is because of their readily availability as a domestic resource in rural communities and can reduce the dependency on fossil fuels. Waste to Energy (WTE) technologies such as biogas technology, therefore should be extensively employed for the utilization of animal manure and to mitigate the climate change occasioned by the unscientific management of animal manure [4] Anaerobic digestion (AD) of livestock manure for biogas production does not reduce its value as a soil conditioner or a fertilizer supplement because the available nitrogen, ammonium, and other mineral nutrients that remain in the digestate are considerable enough to support plant growth $[5,6]$.

The significance of $A D$ as an ecofriendly approach to waste management and biogas production has triggered off several research efforts on the different ways to improve process stability, biomass conversion efficiency, and enhance biogas production. Improving the compositional characteristics of substrates by anaerobic co-digestion of one substrate with another at different ratios is one of the methods that have been extensively investigated and widely adopted in enhancing biogas yield. For example, anaerobic co-digestion of animal manure with kitchen wastes [7-9], animal manure with straw [10-12], with water Hyacinth [13-16], with dedicated energy crops [17,18], animal manure with another [19-21] and sewage sludge [22] have been reported.

The microbiology/biochemical processes and operational characteristics of bio-digesters have led to the development of different designs and types of bio-digester, batch mode, sequencing batch, and continuous bioreactors. To develop an efficient and very reliable design of biodigester and assess its efficiency and performance, appropriate mathematical models describing the process are important [23]. There are several documented mathematical models such as models for calculating biogas production based on stoichiometry, and models based on reaction kinetics which also take into consideration, product inhibition, substrate limiting, etc [24,25]. 
Biogas production process contains several complex interconnections. The different parameters required to characterize the process complicates the development of a well intelligible model. However, several kinetics models have been developed and applied in describing anaerobic digestion process [26-30]. Several compositional analyses conducted on agrowastes [31,32] have shown that they are highly complex and multi-component in nature, some with two or more carbon and energy sources such as lignocellulose, starch, fat, etc. During anaerobic digestion and biogas production, if two or more of these complex compounds are present in the medium, microbial growth will occur preferentially on the fast metabolizable substance. This is followed by a temporary growth cessation (another lag period) before the utilization of the others. The trade-off between fast metabolized substrate before the switch-off to the slowly metabolized substrate is known as biphasic or diauxic growth. It is a phenomenon whereby a population of microorganisms, when presented with two or more carbon and energy sources, exhibits biphasic exponential growth intermitted by a lag-phase of minimal growth [33]. The consequence of this is that biogas production will occur in phases, with periods of low and accelerated biogas yield (multiple peaks). Kinetic assessment of biphasic or diauxic-like anaerobic digestion (AD) process of livestock manures using bi-logistic function model is very rare in the literature. To fill the existing gaps in this field of study, this work investigated the feasibility of simulation of diauxic-like or biphasic biogas production process from anaerobic digestion of mixtures of livestock manures using bi-logistic function and modified Gompertz equation.

\section{MATERIALS AND METHODS}

Three livestock manure, poultry manure, pig, and cow dung were used in this study. The cow dung (CD) was collected from an abattoir while the pig dung (PD) and poultry manure (PM) were obtained from within the Federal University of Technology, Owerri, Imo State, Nigeria. Prior to anaerobic digestion, the samples were sun-dried, objectionable solids removed and the particle size reduced by grinding and sieving. The proximate compositions of the samples were determined by adopting standard methods [34].

\subsection{Experimental Set-Up and Biogas Production}

The experiment was designed such that PD/CD was co-digested at varying ratios: $1: 1,2: 1$, and $3: 1, C D / P M$ were digested in like manner while $\mathrm{CD}$ and PD alone served as the control. Slurries of the different mixed ratios were prepared with water and subsequently fed into labeled $10 \mathrm{~L}$ capacity bioreactors. The picture of the experimental set-up is shown in Fig. 1 and the details of the bioreactor content in Table 1. The reactors were inoculated with strained liquor of fresh cow rumen waste (inoculum), and the effective volume of $8 \mathrm{~L}$ was achieved by adding water. After thorough mixing, the initial $\mathrm{pH}$ of the slurry was adjusted to 7.50 using $\mathrm{NaOH}$.

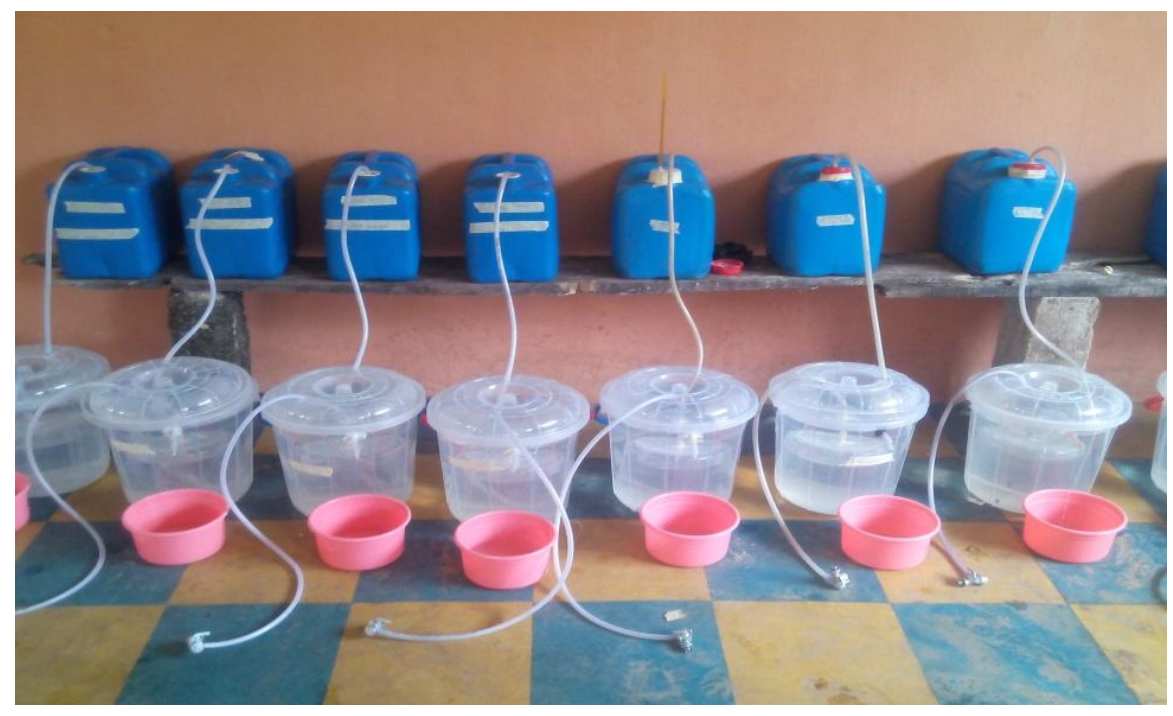

Fig. 1. Picture of the experimental set-up 
Table 1. Details of bioreactor content

\begin{tabular}{llllll}
\hline Treatments & Treatment Ratios & TS (\%) & VS (\%) & Inoculum (L) & Final Volume (L) \\
\hline PD/CD & PD/CD 1:1 & 5.88 & 4.18 & 1.6 & 8 \\
& PD/CD 2:1 & 5.76 & 4.28 & & \\
& PD/CD 3:1 & 5.74 & 4.33 & & 8 \\
CD/PM & PD Alone & 5.70 & 4.48 & & \\
& CD/PM 1:1 & 5.79 & 4.14 & 1.6 & \\
& CD/PM 2:1 & 5.82 & 4.05 & & \\
& CD/PM 3:1 & 5.83 & 4.01 & & \\
& CD Alone & 5.88 & 3.89 & & \\
\hline
\end{tabular}

The reactors were properly sealed and the biogas outlet connected to the biogas harvesting system previously filled with water and allowed to overflow. Anaerobic digestion (AD) was under a temperature range of $25-35^{\circ} \mathrm{C}$ and the $\mathrm{pH}$ of the digesting slurry was read with a digital $\mathrm{pH}$ meter at alternate days and maintained at $7.0-7.80$ throughout the fermentation period which lasted for 84 days. Daily biogas produced in each of the reactors, collected by the downward water displacement method was measured after manual agitation. The effect of the test parameters on anaerobic digestion was evaluated by the maximum cumulative biogas yield.

Kinetic Modeling: Two kinetic models, the modified Gompertz model (Equation 1), and bilogistic function models (Equation 2) were used to simulate the mean cumulative biogas yield obtained from the experiments. Selection of the most suitable kinetic model should not only be to predict the efficiency of particular bioreactors, but also to analyze correctly, the metabolic pathways and mechanisms involved during the anaerobic digestion [35].

$$
Y_{t}=Y_{m} \cdot \exp \left\{-\exp \left[\frac{U \cdot e}{Y_{m}}(\lambda-t)+1\right]\right\}
$$

Where:

$Y_{t}=$ the cumulative biogas production $\left(\mathrm{dm}^{3}\right)$

$Y_{m}=$ the biogas production potential $\left(\mathrm{dm}^{3}\right)$

$U=$ the maximum biogas production rate $\left(\mathrm{dm}^{3} /\right.$ day)

$\lambda=$ Lag phase period (days)

$t=$ cumulative time for biogas production (days)

$e=$ mathematical constant $(2.718282)$

The modified Gompertz equation [36] was fitted into the experimental data to predict rate of biogas with assumption that biogas production rate in batch system is a function of the specific growth rate of methanogenic bacteria in the digester. The maximum specific biogas production rate $(U)$, lag phase time $(\lambda)$, and biogas production potential $(\mathrm{Ym})$ were estimated by performing non-linear regression analysis with aid of Sigma Plot version 10.0.

Because the anaerobic digestion process mirrored diauxic growth pattern with multiple peaks of biogas production, the logistic function model [35] was modified as shown in equation 2. The equation was fitted into the experimental values, and kinetic constants generated by nonlinear regression analysis the same software.

$$
y=\frac{P_{b 1}}{1+\exp \left[\frac{4 R_{m 1}\left(\lambda_{1}-t\right)}{P_{b 1}}+2\right]}+\frac{P_{b 2}-P_{b 1}}{1+\exp \left[\frac{4 R_{m 2}\left(\lambda_{2}-t\right)}{P_{b 2}-P_{b 1}}+2\right]}
$$

Where:

$y$ is the biogas yield $\left(\mathrm{dm}^{3}\right)$ with respect to time $t$ (days)

$P_{b 1}$ is the maximum biogas potential of the substrate $\left(\mathrm{dm}^{3}\right)$ before the second lag

$P_{b 2}$ is the maximum biogas potential of the substrate $\left(\mathrm{dm}^{3}\right)$ in the second phase

$R_{m 1}$ is the maximum biogas production rate $\left(\mathrm{dm}^{3}\right)$ before the second lag

$R_{m 2}$ is the maximum biogas production rate (dm3) in the second phase

$\lambda_{1}$ is the first lag phase time (days)

$\lambda_{2}$ is the second lag phase time (days)

$t$ is the time (days).

Statistical analysis (ANOVA) of cumulative biogas yield from the different treatments was carried out using Post-Hoc Duncan test implemented in IBM SPSS statistics software version 20.0 .

\section{RESULTS}

\subsection{Proximate Composition of the Substrates}

On dry weight basis, the proximate compositions of the different livestock manure are presented in 
Table 2. Two very important parameters, the $\mathrm{C} / \mathrm{N}$ ratio and volatile solids (VS) contents of PD are 10.00 and $68.84 \%$; the CD contained 37.00 and $59.77 \%$, whereas PM had 15.00 and $67.62 \%$, respectively.

\subsection{Biogas Production}

The anaerobic digestion (AD) and daily biogas production profile for the different ratios of $\mathrm{PD} / \mathrm{CD}$ are shown in Fig. 2. The lag phase lasted for 8 days in PD/CD $1: 1$ and 13 days in PD/CD $3: 1$, the first 14 days in PD/CD 2:1 and PD alone recorded very low non-flammable gas production. The peaks of gas production were on day 21 in PD/CD 1:1 (2390 ml); day 23 (1430 ml) and day 31 (1500 ml) in PD/CD 2:1; and day 22 (2920 ml) in PD 3:1, whereas multiple peaks were observed in the anaerobic digestion of PD alone. The flammability test indicated that the biogas became flammable on the 16th and 18th day in PD/CD1:1 and PD/CD 3:1, whereas in $\mathrm{PD} / \mathrm{CD} 3: 1$ and $\mathrm{PD}$ alone the biogas became flammable on the 21st day.

A similar pattern of $A D$ and gas production was observed in CD/PM (Fig. 3). The lag period was for 11 days in CD/PM $1: 1$ and 5 days in CD/PM 2:1, CD/PM 3:1 and CD alone. The peak of biogas production was recorded on day $22(2710$ $\mathrm{ml})$ in CD/PM; 18th $(1800 \mathrm{ml})$ and 19th $(1720 \mathrm{ml})$ day in CD/PM 2:1. Two peaks (19th and 22nd day) of gas production were also observed in CD/PM 3:1, with $1850 \mathrm{ml}$ and $1903 \mathrm{ml}$, respectively.

The maximum cumulative biogas yield in the different ratios and the corresponding percentage increase and inhibition in biogas production are summarized in Fig. 4. PD/CD 1:1 and PD/CD 3:1 showed 3.74 and $6.96 \%$ increase in biogas yield; CD/PM $1: 1$ and CD/PM 3:1 was 16.80 and $6.11 \%$, respectively. Inhibitory effects were recorded in PD/CD 2:1 and CD/PM 2:1.

Statistical analysis (ANOVA) revealed no significant difference in biogas yield in any of the treatments relative to the control, but indicated a significant difference $(P \leq 0.05)$ in cumulative biogas yield from $\mathrm{PD}$ alone compared to $\mathrm{CD}$ alone, and significant inhibition in PD/CD 2:1.

\subsection{Kinetic Study}

Plots of simulation of experimental data from the different ratios of $P D / C D, C D / P M$, and control with modified Gompertz model are shown in Figs. 5 and 6 . The kinetic constants estimated using the non-linear regression is presented in Table 3. The anaerobic digestion process was well described by the modified Gompertz model, with a correlation coefficient $\left(R^{2}\right)>0.98$. Similarly, the experimental data were also simulated using bi-logistic function equation. The bi-logistic model fitted properly and much better than the modified Gompertz model as it captured all the curves (Figs. 7 and 8 ), with $R^{2}>0.99$. Due to the biphasic nature of the anaerobic digestion process, two sets of model parameters $\left(\mathrm{Pb}_{1}\right.$; $\mathrm{Rm}_{1} ; \lambda_{1}$ and $\mathrm{Pb}_{2} ; \mathrm{Rm}_{2} ; \lambda_{2}$ ) were generated, as presented in Table 4, and the correlation coefficients $\left(R^{2}\right)$ which indicate the goodness of fit of the models for the experiments are shown in Table 5.

\section{DISCUSSION}

The results of this study showed an increase in cumulative biogas yield in some of the mixtures of $\mathrm{PD} / \mathrm{CD}$ and $\mathrm{CD} / \mathrm{PM}$ compared to PD and CD alone. The treatments did not significantly improve biogas production relative to the control (Fig. 4); however, a significant difference in biogas production was recorded in PD alone, with $57.14 \%$ higher than CD alone. This may be among other factors, attributed to the higher volatile solids (VS) content of PD. This finding is in agreement with Olufemi et al. [37]. The results of their study revealed that co-digestion of chicken droppings and cow dung increased biogas yield as compared to pure samples of either chicken droppings or cow dung. Kafle and Kim [38] evaluated the performance of anaerobic digesters using a mixture of apple waste (AW) and swine manure (SM). The studies were carried out using both batch and continuous digester. The results showed that mixture of AW and SM improved the biogas yield by approximately $16 \%$ and $48 \%$ at mesophilic and thermophilic temperatures, respectively, relative to SM alone, but no statistical difference was found in the methane yield.

Ambient temperature kinetic assessment of biogas production from co - digestion of horse and cow dung was evaluated by Yusuf et al. [39]. The result showed that biogas yield was optimized when horse and cow dung was mixed at a ratio of 3:1.

There was a significant inhibitory effect on biogas production in the bioreactor with PD/CD 2:1. It is apparent from these results and previous studies [40], that the improvement of biogas yield by cosubstrate digestion is among others, a function of the mixing ratio which is in turn dependent on the 
compositional characteristics of the bioreactor feeds. To improve biogas yield by co-substrate digestion, it is therefore imperative to determine the compositional characteristics of the individual substrates and the ratio at which they must be blended. Optimum performance in anaerobic digestion requires suitable conditions such as mixing, substrate, $\mathrm{C} / \mathrm{N}$ ratio, $\mathrm{pH}$, temperature, Hydraulic retention time (HRT), and Organic loading rate, have to be established to keep the microbial population in balance [41]. Co-digestion dilutes the inhibitory substances in substrates, balances the micro and macronutrients, increases the organic loading with concomitant higher biogas yield per unit of digester volume; lastly, diversify and synergizes the microbial communities which play a pivotal role in the methanogenesis [42].
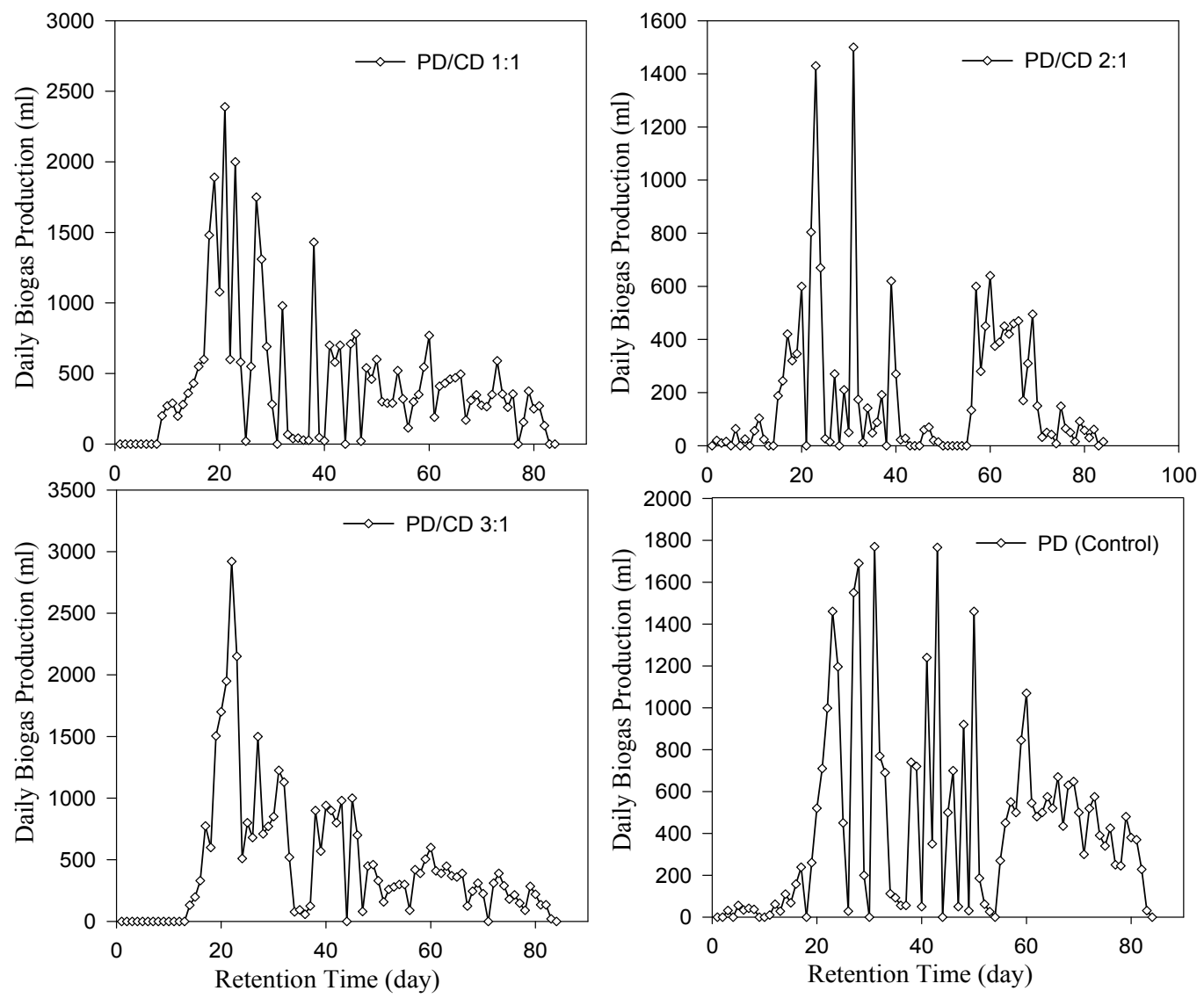

Fig. 2. Anaerobic digestion pattern and daily biogas production from mixtures of $P D / C D$

Table 2. Proximate composition of the substrates

\begin{tabular}{llll}
\hline Parameters (\%) & PD & CD & PM \\
\hline Moisture content (MC) & 12.36 & 9.55 & 12.38 \\
Ash content & 18.80 & 30.68 & 20.14 \\
Fibre & 21.09 & 30.30 & 30.99 \\
Nitrogen & 5.60 & 1.45 & 3.45 \\
Crude Protein & 35.00 & 9.06 & 21.58 \\
C/N ratio & 10.00 & 37.00 & 15.00 \\
Fat content & 4.46 & 2.89 & 3.92 \\
Total Organic Carbon & 53.00 & 54.26 & 50.00 \\
Total Solids (TS) & 87.64 & 90.45 & 87.63 \\
Volatile Solids (VS) & 68.84 & 59.77 & 67.62 \\
\hline
\end{tabular}



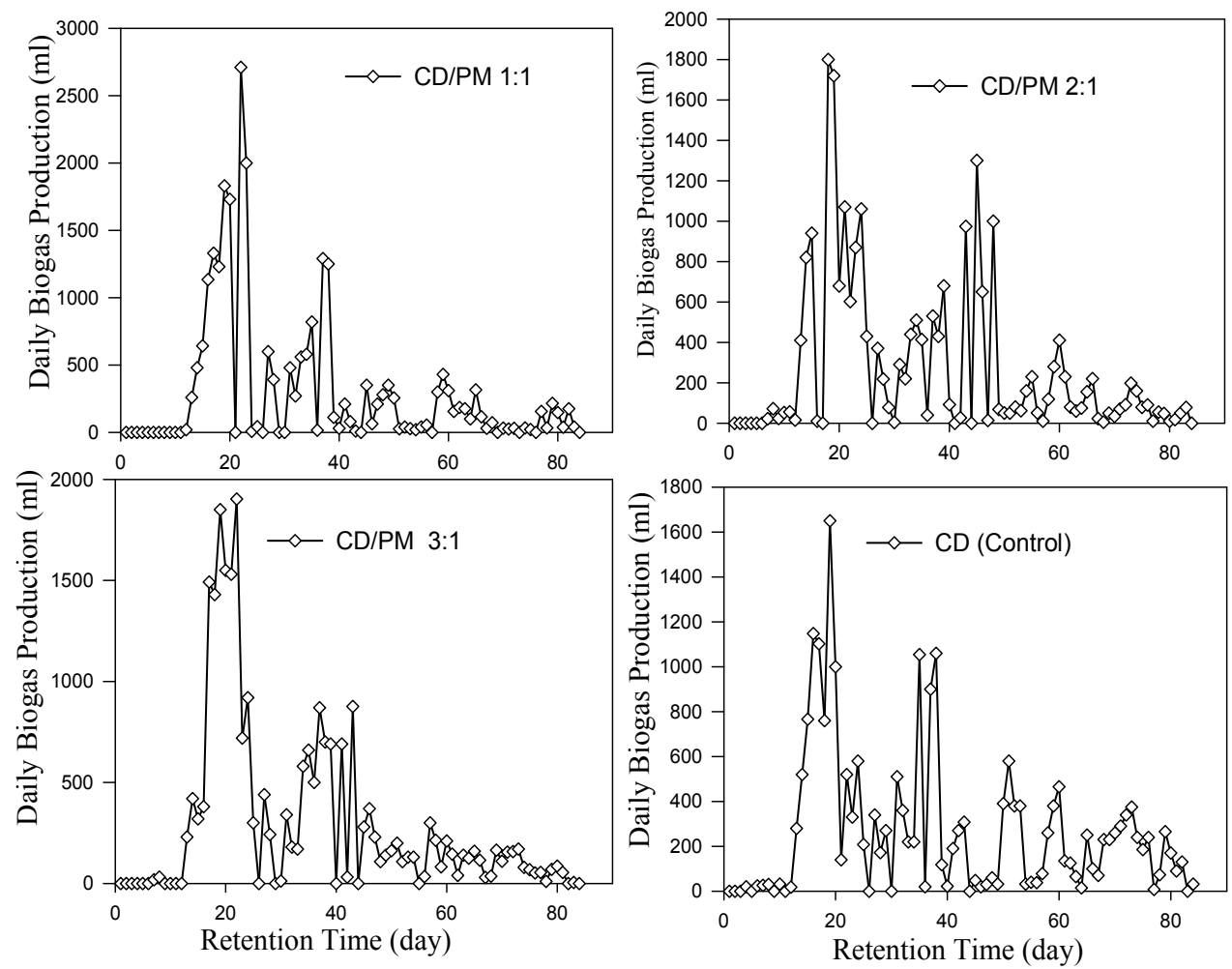

Fig. 3. Anaerobic digestion pattern and daily biogas production from mixtures of CD/PM

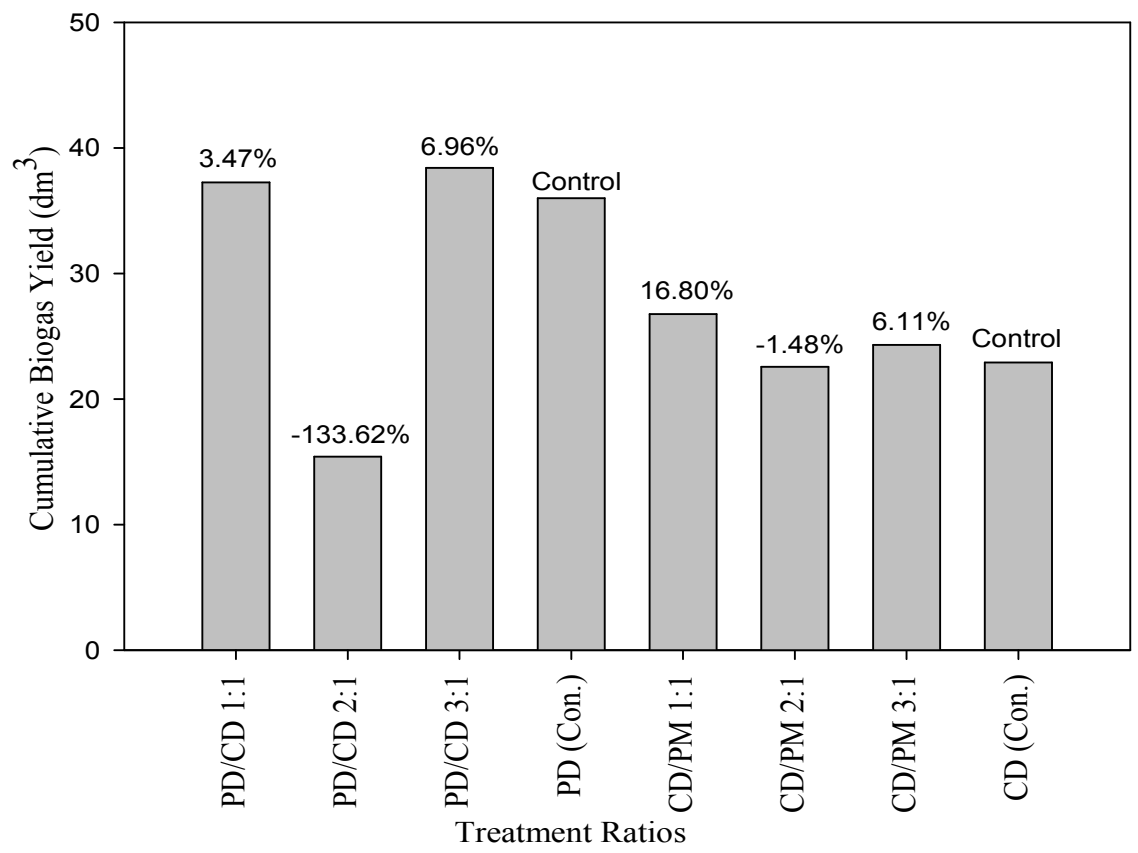

Fig. 4. Cumulative biogas yield from the treatments and the percentage increase and inhibition 


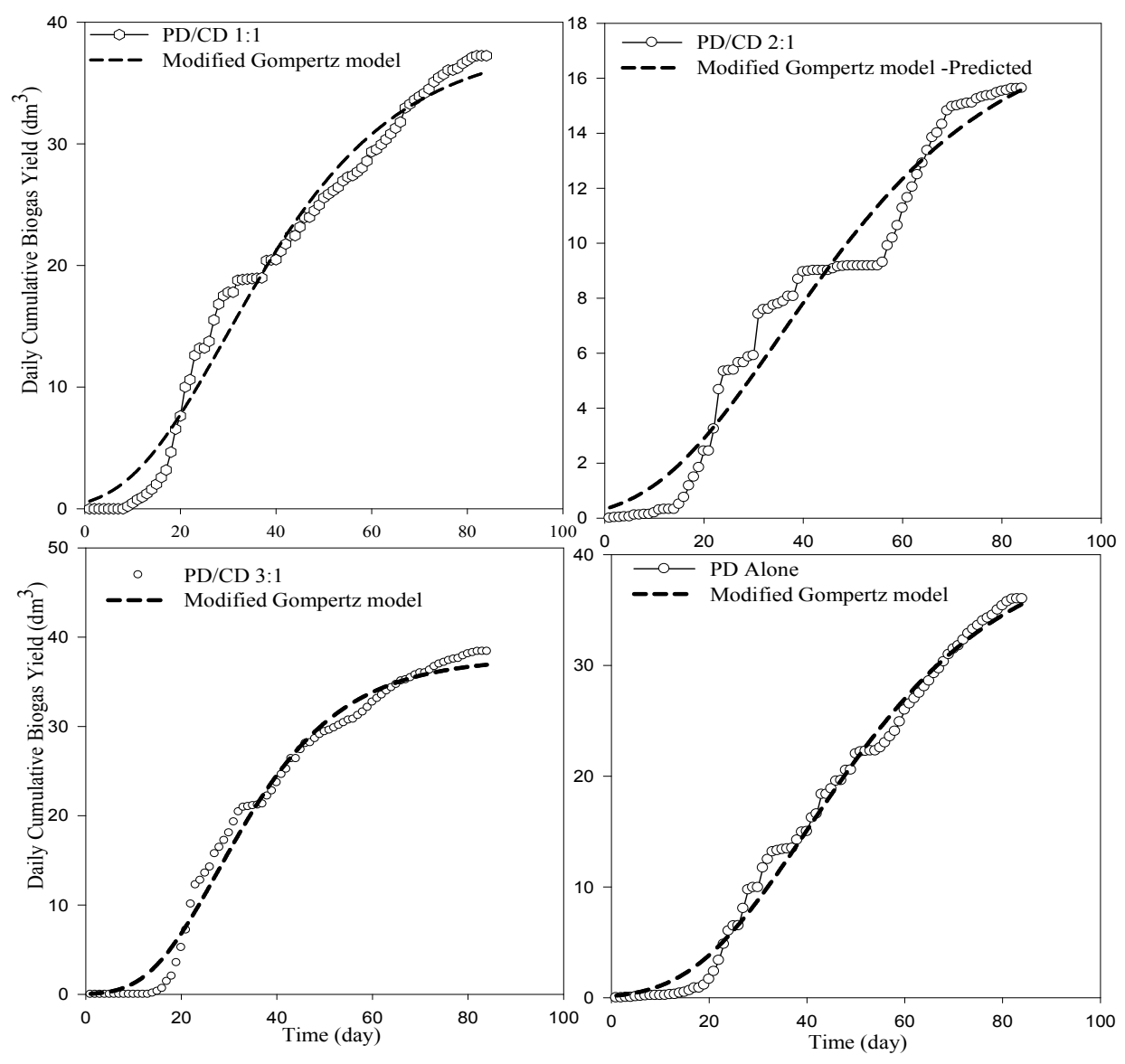

Fig. 5. Simulation of experimental data from of PD/CD ratios with modified gompertz model

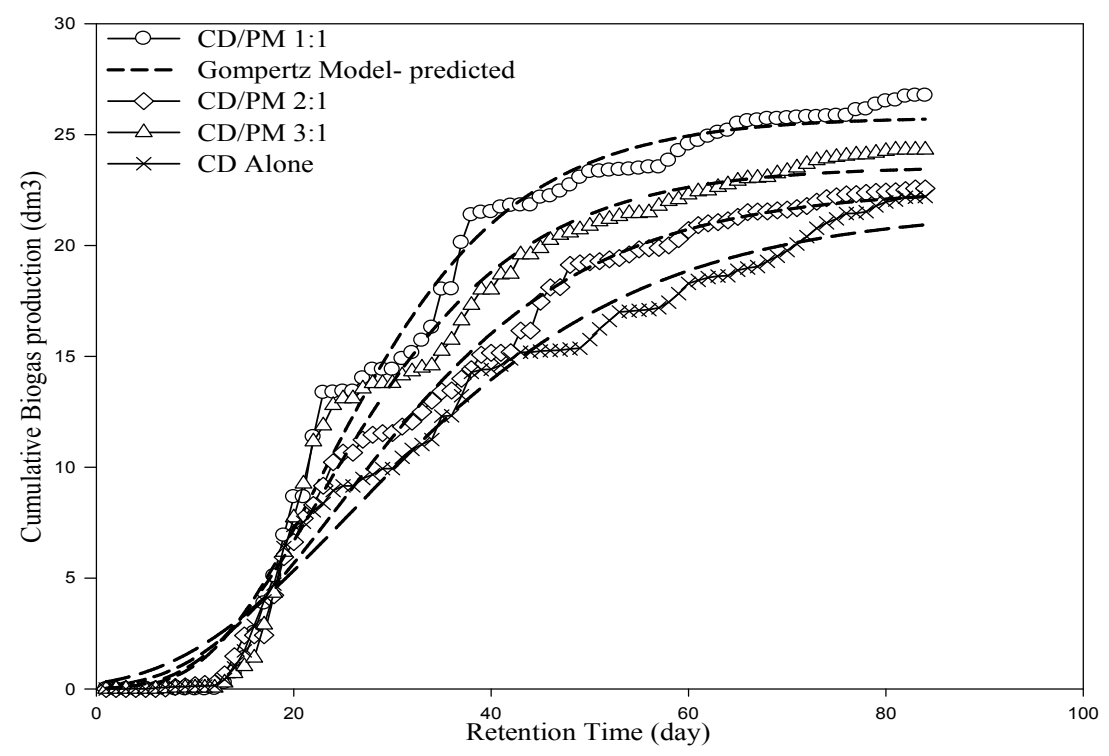

Fig. 6. Simulation of experimental data from of CD/PM ratios with modified gompertz model 


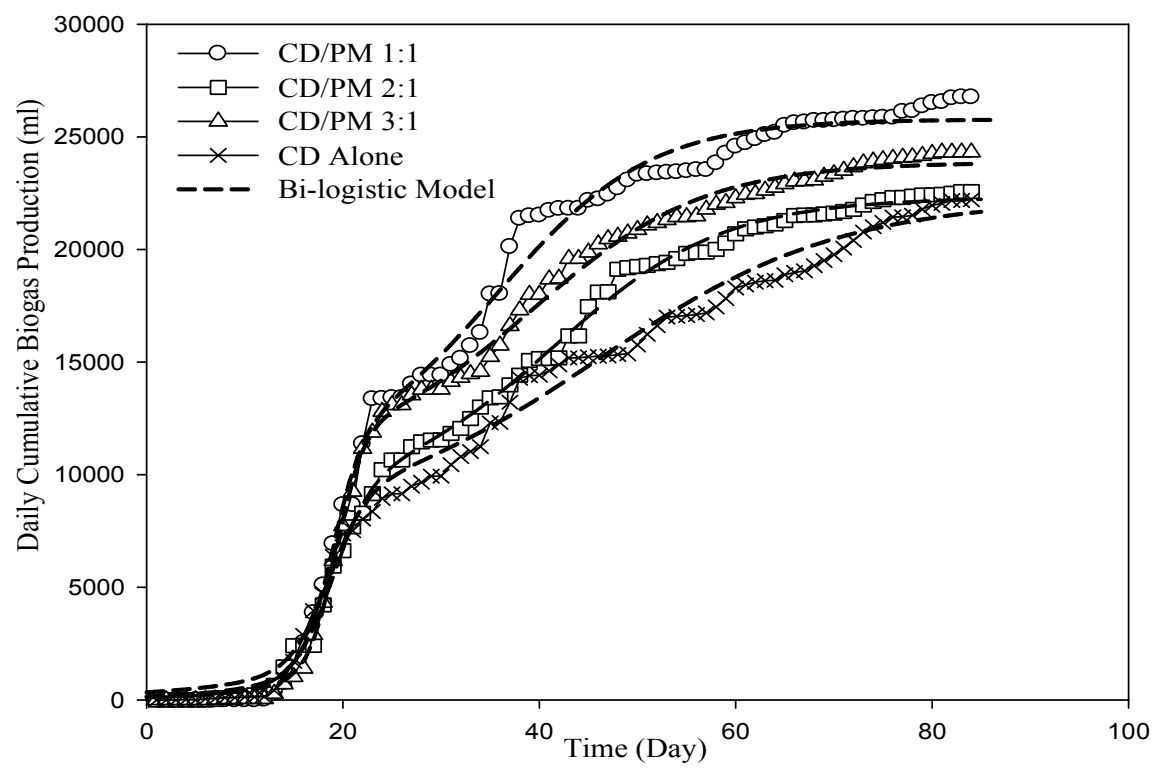

Fig. 7. Simulation of experimental data from of CD/PM ratios with bi-logistic function model
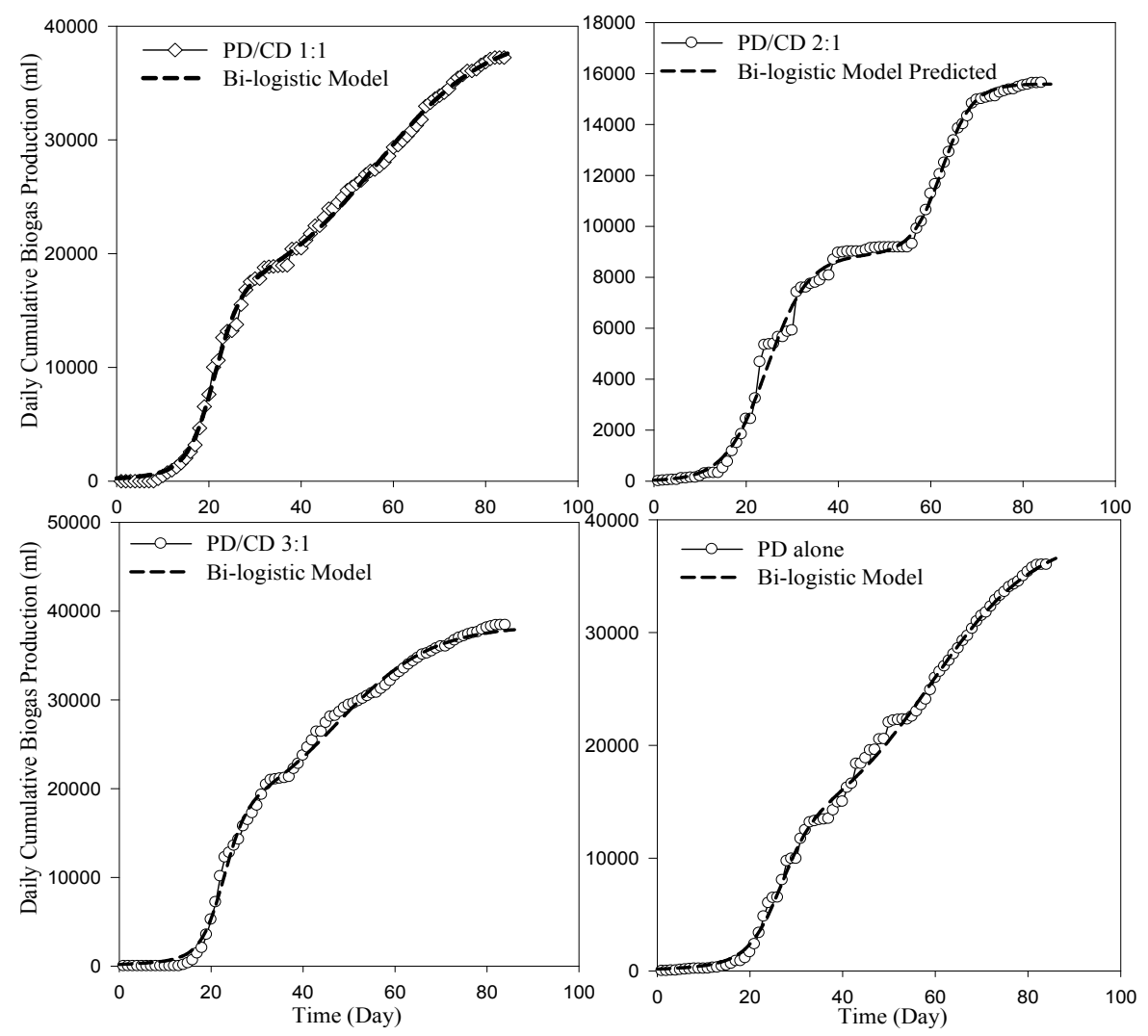

Fig. 8. Simulation of experimental data from of PD/CD ratios with bi-logistic function model 
Table 3. The kinetic constants estimated using modified gompertz model

\begin{tabular}{llll}
\hline Treatments & $\mathbf{Y m}\left(\mathbf{d m}^{\mathbf{3}}\right)$ & $\boldsymbol{U}\left(\mathbf{d m}^{\mathbf{3}}\right)$ & $\boldsymbol{\lambda}$ (Day) \\
\hline PD/CD 1:1 & 38.38 & 0.70 & 9.34 \\
PD/CD 2:1 & 112.46 & 1.12 & 4.55 \\
PD/CD 3:1 & 37.67 & 0.96 & 13.31 \\
PD & 41.43 & 0.65 & 16.87 \\
CD/PM 1:1 & 25.79 & 0.86 & 11.73 \\
CD/PM 2:1 & 22.56 & 0.56 & 10.32 \\
CD/PM 3:1 & 23.56 & 0.75 & 11.08 \\
CD & 21.67 & 0.46 & 8.56 \\
\hline
\end{tabular}

Table 4. Kinetic constants estimated using bi-logistic function model

\begin{tabular}{|c|c|c|c|c|c|c|c|}
\hline \multirow[t]{2}{*}{ Treatment } & \multirow{2}{*}{$\begin{array}{l}\text { Treatment } \\
\text { Ratio }\end{array}$} & \multicolumn{5}{|c|}{ Bi-Logistic model parameters } & \multirow[b]{2}{*}{$\lambda_{2}$ (days) } \\
\hline & & $\begin{array}{l}P b_{1} \\
\left(d m^{3}\right)\end{array}$ & $R_{m 1}\left(d m^{3} \cdot d\right)$ & $\begin{array}{l}\lambda \\
\text { (days) }\end{array}$ & $P_{b 2}\left(d m^{3}\right)$ & $\mathrm{R}_{\mathrm{m} 2}\left(d m^{3} \cdot d\right)$ & \\
\hline \multirow[t]{4}{*}{$\mathrm{PD} / \mathrm{CD}$} & PD/CD 1:1 & 15.88 & 1.40 & 15.57 & 39.73 & 0.49 & 31.76 \\
\hline & PD/CD 2:1 & 8.91 & 0.50 & 15.58 & 15.49 & 0.50 & 55.86 \\
\hline & PD/CD 3:1 & 16.63 & 1.71 & 17.93 & 38.39 & 0.54 & 27.47 \\
\hline & PD Alone & 11.96 & 0.88 & 19.85 & 38.97 & 0.58 & 35.93 \\
\hline \multirow[t]{4}{*}{ CD/PM } & CD/PM 1:1 & 10.46 & 1.71 & 15.96 & 25.78 & 0.50 & 20.46 \\
\hline & CD/PM 2:1 & 9.11 & 1.14 & 15.00 & 22.30 & 0.39 & 24.41 \\
\hline & CD/PM 3:1 & 10.98 & 1.95 & 16.52 & 23.87 & 0.37 & 22.30 \\
\hline & CD Alone & 7.95 & 1.02 & 14.73 & 22.26 & 0.29 & 22.20 \\
\hline
\end{tabular}

Table 5. Goodness of fit for the experiments

\begin{tabular}{lll}
\hline Experiment & \multicolumn{2}{c}{ Correlation Coefficients $\left(\mathbf{R}^{2}\right)$} \\
\cline { 2 - 3 } & Modified Gompertz Model & Bi-logistic Function Model \\
\hline PD/CD 1:1 & 0.9797 & 0.9985 \\
PD/CD 2:1 & 0.9968 & 0.9967 \\
PD/CD 3:1 & 0.9877 & 0.9970 \\
PD & 0.9913 & 0.9978 \\
CD/PM 1:1 & 0.9880 & 0.9942 \\
CD/PM 2:1 & 0.9889 & 0.9981 \\
CD/PM 3:1 & 0.9931 & 0.9977 \\
CD & 0.9901 & 0.9920 \\
\hline
\end{tabular}

The characteristics of the three animal manures used in this study as shown in the results, especially the $\mathrm{C} / \mathrm{N}$ ratio, TS, and VS content suggest their suitability as feedstock in anaerobic digestion and biogas production. Cow dung, being excreta from a ruminant animal is known to contain the autochthonous microbial flora that aids in faster biogas production. It has also been severally reported that cow dung is a very good starter for poor biogas-producing feedstocks [43]. The high VS and nitrogen content, coupled with the low $\mathrm{C} / \mathrm{N}$ ratio of the poultry manure makes is a suitable substrate for co-digestion with other substrates with high carbon but low nitrogen content [1]. Though the cumulative biogas yield from $\mathrm{PD}$ alone is relatively high compared to $\mathrm{CD}$ alone, the low $\mathrm{C} / \mathrm{N}$ ratio of $\mathrm{PD}$ underscores the need to improve the compositional characteristics of PD through co-digestion with a nitrogen-rich substrate to further enhance biogas production.

As indicated by the plots of anaerobic digestion (AD) and daily biogas production from the different treatments, microbial activities followed a similar trend in all the digesters. The initial lag phase was above 10 days in some treatments, followed by an active period of biogas production which subsequently declined and finally stopped. Biogas was low at the beginning and the end of the experiment; this implies that the biogas produced in batch conditions corresponds to the specific growth rate of methanogenic bacteria [20]. To be fully effective, microbial populations in 
bioreactors and their adaptation to the new environmental conditions typically take a significant period to establish themselves [44].

At the initial stage of $A D$, the aerobic bacteria use up the available $\mathrm{O}_{2}$ trapped in the bioreactor to breakdown complex organic compounds into simpler forms, releasing $\mathrm{CO}_{2}$. As the amount of $\mathrm{O}_{2}$ available in the bioreactor is being used up, there is a corresponding decrease in the amount of $\mathrm{CO}_{2}$ produced until all the oxygen is completely exhausted. At this point, the aerobic bacteria are succeeded by the anaerobic and facultative anaerobes, and this halts their activities and methanogenic activities take over the stage. The methane forming bacteria have a very slow growth rate, explaining the gradual rise in gas production after the initial low yield [19]. It could also be explained that when the bioreactors were initially charged, acid formingbacteria quickly produced acid which results in a decline in $\mathrm{pH}$ below neutral, which decreases the growth of methanogenic bacteria and consequently, methanogenesis [45].

In the course of the AD of the mixtures of the feedstocks, biogas production started after a period of relative inactivity (lag phase). The initial rise in gas production was followed by a period of steady-state in gas production, and subsequently, an acceleration in gas yield before it slowly declined. The result of this pattern was multiple peaks in biogas production as indicated in the plots. This phenomenon suggested a biphasic or diauxic-like behavior in the microbial growth and utilization of the complex mixture of substrates in the bioreactors, as was deduced from the successive appearance of multiple peaks in the biogas production profiles. The phenomenon whereby a microbial population, when presented with two or more carbon and energy sources, exhibits biphasic exponential growth intermitted by a period of lag-phase of minimal growth is knowns as diauxic or biphasic growth [33]. The diauxic growth pattern and biogas production profile demonstrate the complex and multi-component nature of the organic wastes in the bioreactors. The presence of compounds such as lipids, carbohydrates, and proteins, which are precursors of intermediate inhibitory compounds, such as long-chain fatty acids and ammonia could be responsible for the observed diauxic growth pattern and bi-phasic biogas production [46].

Diauxic growth pattern for several complex organic substrates such as substrates rich in fat, protein, or lignocellulose has been reported [47], and is mostly ascribed to the fact that microbial populations are exposed to two or more substrates which are preferentially metabolized at different rates, resulting in a two-phase reaction. Though, biphasic or diauxic-like biogas production kinetics may also reveal some level of inhibitory effects on the biochemical steps of the biogas production process. A similar pattern of diauxic growth in the utilization of organic substrates observed in this study has been reported by [48], in which a non-linear model of hydrogen production by Caldicellulosiruptor saccharolyticus for diauxic-like consumption of lignocellulosic sugar mixtures was investigated.

The biphasic or diauxic growth pattern and biogas production profile prompted the application of modified Gompertz model and bilogistic function model in the evaluation of the $A D$ process, to ascertain the possibility of capturing the observed curves. And as can be seen in Figs. 4-7, the anaerobic digestion process was suitably described by the modified Gompertz model, however, the bi-logistic function model showed a better performance in the simulation of the generated experimental data, because it was able to capture the curves and therefore, most suitably described the $A D$ process with higher correlation coefficient $\mathrm{R}^{2}$ than modified Gompertz model (Table 5). The high correlation coefficients > 0.99 indicate a very strong relationship between experimental data and model parameters. Two sets of kinetic parameters, $\left(\mathrm{Pb}_{1} ; \mathrm{Rm}_{1} ; \lambda_{1}\right.$ and $\left.\mathrm{Pb}_{2} ; \mathrm{Rm}_{2} ; \lambda_{2}\right)$ were generated using the bi-logistic model. The $\mathrm{Pb}_{2}$ (the maximum biogas potential of the substrate) was significantly higher than $\mathrm{Pb}_{1}$, whereas the $\mathrm{Rm}_{1}$ (maximum biogas production rate) is lower than the $\mathrm{Rm}_{2}$. However, the $\lambda_{1}$ (the predicted lag phase) is much higher than the $\lambda_{2}$. This revealed that the different substrate components biodegraded at different rates $(\mathrm{Rm})$, with different biogas potentials $(\mathrm{Pb})$. The phenomenon of diauxic growth in the anaerobic digestion of complex organic substrates could be captured quantitatively in a kinetic model using bi-logistic function model.

\section{CONCLUSION}

Anaerobic digestion and biogas production technology have proven to be the future of sustainable and eco-friendly agricultural and organic matter-rich industrial waste management pathway. This study showed that co-digestion of $\mathrm{PD} / \mathrm{CD}$ and CD/PM increased biogas production 
at the ratios of $1: 1$ and $3: 1$, whereas $2: 1$ exhibited inhibitory effects. Improvement of biogas production by co-substrate digestion is, among other factors, a function of the mixing ratio which in turn depends on the physicochemical characteristics of the bioreactor feeds. To enhance biogas yield by co-substrate digestion, it is therefore imperative to determine the compositional characteristics of the individual substrates and the ratio at which they must be mixed.

The two models showed good performance in the simulation of the AD process, with high correlation coefficients, an indication of a very strong relationship between experimental data and model parameters. However, the bi-logistic function model showed a better performance in the simulation of the generated experimental data, as it was able to capture the curves in the plots, with a higher correlation coefficient $\mathrm{R}^{2}$ than the modified Gompertz model. One of the findings in this work has shown that the phenomenon of diauxic growth in the anaerobic digestion of complex organic substrates could be captured quantitatively in a kinetic model using the bi-logistic function model. While we recommend further studies in $A D$ using the bilogistic function model, the preliminary results in this research could be valuable in planning for anaerobic digestion of animal manure for biogas production in large scale.

\section{COMPETING INTERESTS}

Authors have declared that no competing interests exist.

\section{REFERENCES}

1. Oyewole OA. Biogas production from chicken droppings. Science World Journal. 2010;5(4):11-14.

2. Ali S, Bashir S, Nasreen Z, Yasmeen A, lqba $\mathrm{R}$, Yaseen $\mathrm{T}$, Usman $\mathrm{S}$, Nazir $\mathrm{S}$. Potentially biogas production from vegetable waste and used from fish growth culture Labeo Rohita. Sky Journal of Agricultural Research. 2014;3(8):152-157.

3. Aderinlewo AA, Layode OF. The effect of plantain peels ash on biogas production from cow dung. Sustainability, Agri, Food and Environmental Research. 2018; 6(1):11-17.

4. Varma CG, Kannan A, Anil KS, Geetha N, Shyama K, Gleeja VL. Co-Digestion of Livestock Manures for Enhanced Biogas
Production. International Journal of Science, Environment and Technology. 2017; 6(3): 2005-2010.

5. Budiyono INW, Johari S, Sunarso. The kinetics of biogas production rate from cattle manure in batch mode. International Journal of Chemical and Biological Engineering. 2010;3(1):39- 44.

6. Aragaw T, Andargie M, Gessesse A. Codigestion of cattle manure with organic kitchen waste to increase biogas production using rumen fluid as inoculums. International Journal of Physical Sciences. 2013;8(11):443- 450.

7. Baek G, Kim D, Kim, J, Kim, H and Lee, C. Treatment of cattle manure by anaerobic co-digestion with food waste and pig manure: Methane yield and synergistic effect. Int J Environ Res Public Health. 2020;17:4737.

Available:www.mdpi.com/journal/ijerph

8. Okareh OT, Adeolu AT, Shittu OI. Enrichment of pig dung with selected crop wastes for the production of biogas. International Research Journal of Microbiology. (IRJM). 2013;4(4):119-124p.

9. Sawyerr N, Trois C, Workneh T. Okudoh V. Co-digestion of animal manure and cassava peel for biogas production in South Africa. 9th Int'l Conference on Advances in Science, Engineering, Technology \& Waste Management (ASETWM-17), Parys, South Africa; 2017.

10. Vivekanandan S, Kamaraj G. The study of biogas production from rice chaff (karukka) as co-substrate with cow dung. Indian Journal of Science and Technology. 2011;4(6):657-659.

11. lyagba E T, Mangibo IA, Mohammad YS. The study of cow dung as co-substrate with rice husk in biogas production. Scientific Research and Essay. 2009;4 (9):861-866.

12. Zhang T, Liu L, Song Z, Ren G, Feng, Y., Han X, Yang G. Biogas production by codigestion of goat manure with three crop residues. Plos One. 2013; 8(6):1-7.

13. Momoh OLY and Nwaogazie LI. Effect of waste paper on biogas production from codigestion of cow dung and water hyacinth in batch reactors. Journal of Applied Sciences and Environmental Management. 2008;12(4): 95-98

14. Nugraha WD, Syafrudin, Senduk AT, Matin HHA, Budiyono. Optimization of Biogas Production by Solid State Anaerobic Digestion (SS-AD) method from water 
hyacinth with Response Surface Methodology (RSM). E3S Web of Conferences. 2018;73(01016):1 - 5.

15. Tasnim F, lqbal SA, Chowdhury A R. Biogas production from anaerobic codigestion of cow manure with kitchen waste and Water Hyacinth. Renewable Energy. 2017;109:434 - 439.

16. Pachaiyappan $S$, Elamvazhuthi $P$, Dhamodharan M, Sundaram S. Biogas production from water hyacinth blended with cow dung. Indian Journal of Energy. 2014;3(1):134-139.

17. Matheri AN, Belaid M, Seodigeng T, Ngila CJ. The kinetic of biogas rate from cow dung and grass clippings. 7th International Conference on Latest Trends in Engineering \& Technology (ICLTET'2015) Irene, Pretoria (South Africa); 2015.

18. Gupta A, Chandra R, Subbarao PMV, Vijay VK. Kinetics of batch Biomethanation Process of Jatropha and Ponamia oil cakes and their Co-digested Substrates. Journal of Scientific and Industrial Research. 2009;68: 624-629.

19. Olowoyeye, J. Comparative Studies on biogas production using six different animal dungs. Journal of Biology, Agriculture and Healthcare. 2013;3(15): 7-12.

20. Membere EA, Ugbebor J, Joshua O. Computational model for biogas production from solid waste. Journal of Environment. 2013;2(2):47- 51.

21. Wante H P, Ngaram S M, Bala G A, and Buba, M. Optimization of Biogas Production from Cow and Goat Manure. International digital organization for scientific research Idosr. Journal of Applied Sciences. 2016;1(1):24-35.

22. Sidik UH, Razali FB, Alwi SRW, et al. Biogas production through Co-digestion of palm oil mill effluent with cow manure. Nigerian Journal of Basic and Applied Science. 2013;21(1):79 - 84.

23. Adamu AA, Aluyor EO. Empirical model for predicting rate of biogas production. Global Journal of Engineering Research. 2013;12: 63-68.

24. Gerber M, Span R. An analysis of available mathematical models for anaerobic digestion of organic substances for production of biogas, International Gas Union Research Conference (IGRC), Paris. 2008;1-30.

25. Manjusha C, Beevi BS. Mathematical modeling and simulation of anaerobic digestion of solid waste. International conference on emerging trends in engineering, science and technology (ICETEST-2015). Procedia Technology. 2016;24(2016):654 - 660.

26. Shitophyta LM. Maryudi comparison of kinetic model for biogas production from corn cob. IOP Conference Series: Materials Science and Engineering. 2018; 345(2018):012004.

27. Jijai S and Siripatana C. Kinetic model of biogas production from co-digestion of thai rice noodle wastewater (khanomjeen) with chicken manure. 2017 international conference on alternative energy in developing countries and emerging economies 2017 AEDCEE, 25 - 26 May 2017, Bangkok, Thailand. Energy Procedia. 2017;138: 386-392.

28. Yan H, Zhao C, Zhang J, Zhang R, Xue C, Liu G, Chen C. Study on biomethane production and biodegradability of different leafy vegetables in anaerobic digestion. AMB Express. 2017;7(27):2- 9.

29. Nnabuchi MN, Akubuko FO, Augustine C. Assessment of the effect of co-digestion of chicken dropping and cow dung on biogas generation. Scholarly Journals of Biotechnology. 2012;1(4): 66-71.

30. Yadvika $\mathrm{H}$ and Thanikal JV. Non-linear kinetic modelling of anaerobic biodegradation of fruit and vegetable waste together with cooked oil. International Journal of Advanced Research in Biological Sciences. 2016;3(5):109-121.

31. Kumar R, Mago G, Balan V, Wyman CE. Physical and chemical characterizations of corn stover and poplar solids resulting from leading pretreatment technologies. Bioresource Technology. 2009;100:39483962.

32. Patil JH, Raja MA, Shankar BB, Shetty MK, Kumard PBP. Anaerobic Co-digestion of water hyacinth and sheep waste. Energy Procedia. 2014;52:572-578.

33. Chu D, Barnes DJ. The lag-phase during diauxic growth is a trade-off between fast adaptation and high growth rate. Scientific Reports. 2016;6(25191):1-15.

34. AOAC. Official methods of analysis, association of official analytical chemists. $19^{\text {th }}$ edition, Washington D.C., USA; 2012.

35. Pramanik SK, Suja FB, Porhemmat M, Pramanik BK. Performance and kinetic model of a single-stage anaerobic digestion system operated at different successive operating stages for the 
treatment of food waste. Processes. 2019; 7(600):1-16.

36. Budiyono IS and Sumardiono S. Kinetic model of biogas yield production from vinasse at various initial $\mathrm{pH}$ : Comparison between modified gompertz model and first order kinetic model. Research Journal of Applied Sciences, Engineering and Technology. 2014;7(13):2798-2805.

37. Olufemi FE, Veronica D, Godwin H. Effect of anaerobic co-digestion on microbial community and biogas production. Biosciences Biotechnology Research Asia. 2019;6(2): 391-401.

38. Kafle GK, Kim SH. Anaerobic treatment of apple waste with swine manure for biogas production: Batch and continuous operation. Applied Energy. 2013;103:6172.

39. Yusuf MOL, Debora A, Ogheneruona DE. Ambient temperature kinetic assessment of biogas production from co-digestion of horse and cow dung. Research in Agricultural Engineering. 2011;57(3):97104.

40. Chukwuma EC, Chukwuma GO. Biogas production potential of co-digestion of pig droppings with cow dung under tropical conditions. British Biotechnology Journal. 2014;4(7):760-768.

41. Adepoju TF, Olatunbosun BE, Olawale O. Statistical analysis of biogas production from co-digestion of cornstalk with goat dung using a one factor design. Chemistry Research Journal. 2016;1(4):1-10.
42. Shah FA, Mahmood Q, Rashid N, Pervez A, Raja IA, Shah MM. Co-digestion, pretreatment and digester design for enhanced methanogenesis. Renewable and Sustainable Energy Reviews. 2015; 42: 627-642.

43. Ofoefule AU, Nwankwo JI, Ibeto CN. Biogas production from paper waste and its blend with cow dung. Advances in Applied Science Research. 2010;1(2):1- 8.

44. Onakughotor ED. Effect of Inoculums on Biogas Yield. Journal of Applied Chemistry (IOSR-JAC). 2015;8(2):05-08.

45. Sirirote $P$, Thanaboripat $D$, Klinkroon $N$, and Tripak, S. The production of biogas from cassava tubers. KMITL Science and Technology Journal. 2010;10 (1): 30-36.

46. Kim MJ, Kim SH. Evaluation of the degradation of carbohydrate-based material during anaerobic digestion for high-efficiency biogas production. Journal of Biosystems Engineering. 2018;43(2): $110-118$.

47. Kim $M$ and Kim $S H$. Minimization of diauxic growth lag-phase for highefficiency biogas production. Journal of Environmental Management. 2016;187.

DOI: 10.1016/j.jenvman. 2016.11.002

48. Björkmalm J, Byrne E, Niel WJV, Willquist, $\mathrm{K}$. A non-linear model of hydrogen production by Caldicellulosiruptor saccharolyticus for diauxic-like consumption of lignocellulosic sugar mixtures. Biotechnology Biofuels. 2018; 11(175):1-15.

(c) 2021 Opurum et al.; This is an Open Access article distributed under the terms of the Creative Commons Attribution License (http://creativecommons.org/licenses/by/4.0), which permits unrestricted use, distribution, and reproduction in any medium, provided the original work is properly cited.

Peer-review history:

The peer review history for this paper can be accessed here: http://www.sdiarticle4.com/review-history/66379 